\title{
RESISTÊNCIA À MUDANÇA: uma revisão crítica
}

\author{
José Mauro da Costa Hernandez \\ Administrador de Empresas pela FEA-USP, Mestre em Administração de Empresas pela FEA-USP \\ e Doutorando em Administração de Empresas pela FGV-EAESP. \\ E-mail: jmhernandez@fgvsp.br
}

\begin{abstract}
Miguel P. Caldas
Administrador de Empresas pela UNB, Mestre e Doutor em Administração de Empresas pela FGV-EAESP,

Professor do Departamento de Administração Geral e Recursos Humanos da FGV-EAESP e Consultor de Empresas.

E-mail:mcaldas@fgvsp.br
\end{abstract}

\begin{abstract}
RESUMO
Ao implementar mudanças ou inovações, as organizações, muitas vezes, têm de enfrentar resistências internas. Por ser a resistência à mudança um dos tópicos mais estudados no campo organizacional, temos sido induzidos a crer que sabemos tudo a seu respeito. Se sabemos tanto, por que a resistência ainda é uma das principais barreiras à transformação organizacional? Neste artigo, tentamos responder a essa indagação questionando os modelos predominantes de resistência e pondo em dúvida os pressupostos das diversas "receitas" recomendadas para lidar com a resistência. Nossa proposição é que tais "receitas" não são de grande ajuda porque estão embasadas em um modelo de resistência construído sob diversos pressupostos discutíveis, segundo os quais a resistência é: a) uma circunstância inevitável; b) nociva à organização; c) um comportamento natural dos seres humanos; d) um comportamento exibido exclusivamente por empregados; e) um fenômeno massificado. Usando contrapressupostos para cada uma dessas premissas clássicas e utilizando a Psicologia da Percepção, o estudo propõe um novo Modelo de Resistência Individual à Mudança. Esse modelo de sete estágios procura representar o processo de percepção individual durante a mudança organizacional, desde a exposição ao estímulo até a adoção de um dado comportamento. Implicações para a teoria e a prática, limitações do modelo e sugestões para pesquisa futura são também apresentadas.
\end{abstract}

\begin{abstract}
When implementing changes and innovations, organizations often have to deal with resistance to change. Maybe because few subjects pertaining to organizational transformation are so broadly and consistently covered in the popular literature, we may have been induced to believe we must know all about it. If we know so much, why resistance is still a major barrier to organizational transformation, and why so many change agents still strive to overcome it? In this article, we attempt to respond this question by questioning the predominant models of resistance and the assumptions of the several "recipe-oriented" approaches to deal with resistance in organizations. Our understanding is that such "recipes" are not particularly helpful because they use a model of resistance to change that was built upon several questionable assumptions, according to which resistance is a) a "natural", inevitable fact; b) malignant to the organization; c) employeedriven; and d) collective. Based on counter-assumptions to each of these widespread premises and on Psychology of Perception, a new Model of Individual Resistance to Change is proposed. The model represents the individual's perceptual process during organizational change, from exposure to stimuli until behavior adoption. The seven-stage model culminates in four possible outcomes: resistance, resistance overcoming, indecision, or change adoption. Implications for theory and practice, limitations of the model and suggestions for future development are presented.
\end{abstract}

PALAVRAS-CHAVE

Resistência à mudança, mudança organizacional, percepção, cognição, organização.

KEY WORDS

Resistance to change, organizational change, perception, cognition, organization. 


\section{INTRODUÇÃO}

A mudança organizacional tornou-se uma das principais atividades para empresas e instituições em todo o mundo. Embora as organizações costumassem mudar esporadicamente, quando necessidades reais e urgentes assim o exigiam, hoje em dia, elas tendem a provocar a sua transformação incessantemente. Organizações mudam para fazer face à crescente competitividade, cumprir novas leis ou regulamentações, introduzir novas tecnologias ou atender a variações nas preferências de consumidores ou de parceiros. Ainda que tanta prática já devesse ter levado à perfeição, a verdade é que a maioria das organizações ainda luta para conduzir transformações de forma efetiva. portamentos resistentes adotados por empregados descontentes que podem impedir ou ameaçar o esforço de transformação. A consistência em conteúdo e discurso de todas essas abordagens de receituários é tão significativa que pode levar-nos a uma conclusão perigosa: a de que tal consistência seja evidência de um fenômeno bem estudado e cuidadosamente mapeado. Em outras palavras, podemos ser tentados a pensar que sabemos tudo a seu respeito ou que, se nós pessoalmente não sabemos tudo sobre resistência, alguém há de saber.

No entanto uma pergunta permanece: se sabemos tanto (sobre como preveni-la ou superá-la), por que a resistência à mudança ainda é considerada uma das principais barreiras à transformação organizacional bem-sucedida?

\section{Tanto a literatura acadêmica quanto a gerencial tendem}

\section{a apontar a resistência à mudança - isto é, qualquer}

\section{conduta que objetiva manter o status quo em}

\section{face da pressão para modificá-lo - como uma das principais barreiras à mudança bem-sucedida.}

A resposta mais provável é que, do ponto de vista científico e a despeito de todas as "receitas", nós, na verdade, não sabemos muita coisa sobre o que é a resistência à mudança, suas causas, quando é mais provável que aconteça, o efeito que pode (ou não) produzir em esforços de transformação ou os métodos que podem existir para lidar com ela. Após ter sido, por tantos anos,

Se os processos de mudança não têm sido completos fracassos, também é verdade que poucos têm sido sucessos estrondosos (Kotter, 1995); a grande maioria situa-se entre esses dois extremos, e as conseqüências são visíveis: perda de tempo, energia e dinheiro, danos à motivação de gerentes e empregados, etc.

Tanto a literatura acadêmica quanto a gerencial tendem a apontar a resistência à mudança - isto é, qualquer conduta que objetiva manter o status quo em face da pressão para modificá-lo (Zaltman e Duncan, 1977) - como uma das principais barreiras à mudança bemsucedida (Kurtz e Duncan, 1998; Coghlan, 1993). Entretanto o único resultado concreto tem sido a proposição de inúmeras "receitas" para se superar a resistência, freqüentemente empoeirando nas estantes de executivos e - com um pouco menos de intensidade na de acadêmicos.

De fato, parece não haver escassez de "receitas" no mercado dirigidas a tratar e superar a resistência à mudança (para uma revisão, ver Kotter e Schlesinger, 1979). Rotuladas sob o nome de "estratégias", geralmente preconizam - sem grande variação de uma para outra ou ao longo do tempo - listas de cinco a dez regras "para viagem", desenhadas para superar com- vastamente analisada e comentada em pesquisas acadêmicas, estudos recentes sugerem que ainda há muito a ser feito para entendermos apropriadamente o fenômeno da resistência à mudança (Dent e Goldberg, 1999; Coghlan, 1993; Agócs, 1997). O presente artigo procura contribuir para a compreensão desse fenômeno ao introduzir uma abordagem individual em vez da abordagem massificada, atualmente predominante - da resistência à mudança. Temos notado que, antes de iniciar esforços de mudança, poucos agentes de mudança ou consultores avaliam meticulosamente quem poderia resistir à iniciativa de transformação específica e por quais motivos. Levando em conta a diversidade de comportamentos que os indivíduos podem assumir, uma avaliação precisa pode não ser intuitiva nem óbvia.

Uma das principais causas da ausência desse tipo de avaliação é a adoção de uma série de pressupostos (sem maior sustentação) sobre a resistência à mudança que sobrevive na maioria dos receituários mais difundidos na literatura gerencial - e, às vezes, acadêmica - sobre o assunto. Este estudo revê tais pressupostos e, baseado, por um lado, em contrapressupostos e, por outro, na Psicologia da Percepção, deriva 
um Modelo de Resistência Individual à Mudança, usando o indivíduo como nível de análise. A hipótese básica do modelo é que a resistência à mudança é um dos possíveis comportamentos que indivíduos podem adotar como resultante da sua percepção sobre a mudança.

O artigo está estruturado da seguinte forma: a seção dois apresenta um breve sumário sobre como a resistência à mudança tem sido comumente descrita na literatura gerencial, concentrando-se particularmente em seus pressupostos tácitos e derivando contrapressupostos sobre o fenômeno de resistência à mudança; a seção três propõe, a partir dos contrapressupostos, um Modelo de Resistência Individual à $\mathrm{Mu}-$ dança; a seção quatro discute as implicações teóricas e práticas do estudo para intervenções de mudança organizacional, e a seção final sumariza o artigo e aponta direções para futuras pesquisas.

\section{"RESISTÊNCIA À MUDANÇA" EM ANÁLISE ORGANIZACIONAL}

\section{Fundamentos conceituais da idéia de "resistência à mudança"}

A expressão "resistência à mudança" geralmente é creditada a Kurt Lewin (1947). Para ele, as organizações poderiam ser consideradas processos em equilíbrio quase-estacionário, ou seja, a organização seria um sistema sujeito a um conjunto de forças opostas, mas de mesma intensidade que mantêm o sistema em equilíbrio ao longo do tempo. Esses processos não estariam em equilíbrio constante, porém mostrariam flutuações ao redor de um determinado nível. As mudanças ocorreriam quando uma das forças superasse a outra em intensidade, deslocando o equilíbrio para um novo patamar. Assim, a resistência à mudança seria o resultado da tendência de um indivíduo ou de um grupo a se opor às forças sociais que objetivam conduzir o sistema para um novo patamar de equilíbrio (Lewin, 1947, 1951).

Lewin acreditava que tanto o indivíduo quanto o grupo poderiam ser considerados "pontos de aplicação" das forças sociais. Segundo ele, o padrão de comportamento do indivíduo poderia ser diferente do padrão de comportamento do grupo ao qual ele pertence, sendo que essa diferença seria permitida ou encorajada em culturas diferentes e em graus diferentes. De forma geral, no entanto, o grupo tenderia a exigir a uniformidade de comportamento dos seus elementos e, quando o indivíduo mostrasse um padrão de comportamento diferente do padrão de comportamento do grupo, ele correria o risco de ser ridicularizado ou até mesmo excluído do grupo. No modelo original de Lewin, a resistência individual poderia ser diferente da resistência grupal, dependendo do valor social dado aos padrões de comportamento no grupo.

Em 1948, Coch e French Jr. publicaram o primeiro estudo empírico sobre "resistência à mudança" no campo organizacional. Esse estudo influenciou grande parte da literatura que se seguiu (Burke, 1987). O tema continuou a despertar interesse principalmente nas décadas de 50 e 60 (Zander, 1950; Lawrence, 1954; Watson, 1969, 1971) e podemos afirmar que essa foi a época mais fértil da discussão sobre o assunto. Nas duas décadas que se seguiram, o tema foi vastamente (não necessariamente de forma apropriada) reproduzido na mídia gerencial, em geral, pelas mesmas linhas traçadas pelo estudo de Coch e French Jr. Depois do relativo silêncio das décadas de 70 e 80 , apenas recentemente a questão da resistência à mudança tem sido estudada novamente como um objeto de pesquisa científica (para uma revisão, ver, por exemplo, Dent e Goldberg, 1999).

\section{"Resistência à mudança" hoje}

Quando se revisa a literatura acadêmica sobre mudança organizacional, dois aspectos parecem bem claros. Primeiro, parece que registramos como uma verdade universal as proposições clássicas - frouxamente modeladas e praticamente não testadas - que foram rascunhadas no final da década de 40 e difundidas como bom senso gerencial nas décadas que se seguiram; segundo, aprendemos, por algum motivo, a considerar a resistência à mudança como um fenômeno natural (Kurtz e Duncan, 1998; Coghlan, 1993) e inevitável, pronto a surgir durante a implementação de mudanças ou inovações em organizações.

Por exemplo, a resistência à mudança foi citada como um dos fatores que prejudicaram processos de implantação da Gerência de Qualidade Total (Liu, 1998; Braver, 1995; Miller e Cangemi, 1993), TQI (Total Quality Improvement) (Holpp, 1989) e Reengenharia (Boyle, 1995). A resistência também foi considerada uma barreira em processos de automação e adoção de computadores no ambiente de trabalho (La Plante, 1991; Joshi, 1991; Poe e Viator, 1990) e em processos de mudança organizacional (Hazan, 1998; Kurtz e Duncan, 1998).

Ao lado da popularização da noção de resistência à mudança como uma das principais barreiras na implantação de processos de mudança e de inovações, foram disseminadas inúmeras "receitas" de como superá-la tanto pela mídia gerencial quanto pela literatura acadêmica. Embora utilizando diferentes terminologias, diversos autores têm sugerido várias estratégias genéricas para se lidar com a resistência às 
mudanças (Iskatt e Liebowitz, 1996; Boyle, 1995; Poe e Viator, 1990). De uma forma ou de outra, todas essas receitas podem ser resumidas nas seis estratégias genéricas apontadas por Kotter e Schlesinger (1979) para se superar a resistência à mudança: a) educação e comunicação; b) participação e envolvimento; c) facilitação e suporte; d) negociação e acordo; e) manipulação e cooperação e f) coerção explícita e/ou implícita.

\section{Uma crítica aos modelos correntes de "resistência à mudança" e aos seus pressupostos}

Já argumentamos neste estudo que, apesar da abundância de "receitas" para lidar com a resistência à mudança sugeridas pela literatura gerencial e acadêmica, elas ainda falham em prevenir a ocorrência de resistência e tampouco têm obtido sucesso expressivo em superá-la. Também sugerimos que isso pode dever-se ao fato de que tal literatura está baseada em a) teorias que foram elaboradas no final dos anos 40 e que foram pouco modeladas ou testadas desde então e b) alguns pressupostos tácitos (embutidos ou derivados dessas teorias) que deveriam ser cuidadosamente revistos.

Obviamente, conjuntos distintos de pressupostos teriam gerado diferentes teorias, e, como é bem sabido, para todo pressuposto, podemos inferir (por oposição) um ou mais contrapressupostos. Acreditamos que é possível propor um modelo de resistência individual à mudança com base na crítica dos modelos tradicionais sobre o assunto, na revisão de seus discutíveis pressupostos e na proposição de contrapressupostos que deles podemos inferir (ver Quadro 1). No restante dessa subseção, iremos propor contrapressupostos que podem ser utilizados para desenhar novas teorias e modelos, dentro e além das fronteiras deste estudo.

Pressuposto $\mathrm{n}^{0} 1$ : A resistência à mudança é um "fato da vida" e algo que inexoravelmente irá ocorrer durante processos de transformação.

O primeiro pressuposto - e provavelmente o menos questionado - nos modelos predominantes de resistência à mudança é o de que a resistência é um "fenômeno natural" (Zander, 1950; Coghlan, 1993) e, por conseguinte, há de ocorrer durante a implantação de toda transformação ou inovação. No entanto, em anos recentes, esse pressuposto tem sido posto em dúvida. Em primeiro lugar, essa premissa tem sido questionada por estudos em mudança organizacional que têm indicado que a resistência não é um fenômeno tão freqüente quanto se possa imaginar (Kotter, 1995). Mediante o estudo de mais de uma centena de organizações de diferentes tamanhos e nacionalidades ao lon- go de uma década, Kotter descobriu que a resistência era rara e que os empregados freqüentemente entendiam a nova visão e queriam contribuir para seu alcance. De acordo com ele, quando a resistência acontece, ela reside comumente na mente do indivíduo e, quando tais impedimentos de fato existem, o obstáculo pode estar na estrutura organizacional, em um sistema de recompensa baseado em desempenho que força as pessoas a escolherem entre a nova visão e seus próprios interesses ou - até pior - em gerentes que se recusam a mudar e que demandam de seus subordinados coisas que são totalmente incompatíveis com todo o esforço de mudança. Esses resultados levam-nos a formular o seguinte contrapressuposto: Contrapressuposto $\mathrm{n}^{0} 1 \mathrm{a}$ : A resistência à mudança é rara e deverá ocorrer somente na presença de circunstâncias excepcionais.

Em segundo lugar, esse pressuposto foi também questionado por argumentos como aquele apresentado por Dent e Goldberg (1999) que sugeriram que os agentes da mudança (gerentes, consultores, etc.), ao considerarem a resistência à mudança como um fenômeno natural e que deve ser superado, incluirão tal circunstância em seu planejamento e criarão formas de minimizá-la. Assim, serão tentados a disfarçá-la ou escondê-la ou, ainda, a tomar todas as iniciativas para superá-la. Agindo dessa maneira, de acordo com Dent e Goldberg, os agentes da mudança acabam provocando o desastre: as mesmas ferramentas que deveriam servir para evitar a resistência ou pelo menos reduzir os seus efeitos acabam contribuindo, irremediavelmente, para o seu aparecimento. Desse modo, a resistência passa, até certo ponto, a ser uma espécie de profecia auto-realizadora, levando ao segundo contrapressuposto:

Contrapressuposto $\mathrm{n}^{0}$ 1b: Ao procurar evitar ou prevenir a resistência, os agentes da mudança acabam contribuindo para a sua ocorrência ou agravamento.

E, em terceiro lugar, esse pressuposto tem sido questionado por teóricos e estudos que discutem o poder nas organizações (Burke, 1987; Agócs, 1997) e que têm defendido que, ao serem manipulados por agendas gerencialistas, os modelos predominantes podem ter sido usados como desculpa ou disfarce pelos detentores de poder e/ou pelos agentes de mudança, em prol de seus próprios interesses, durante processos de transformação.

Contrapressuposto $\mathrm{n}^{0} 1 \mathrm{c}$ : A resistência é um comportamento definido pelos detentores de poder quando são desafiados em seus privilégios ou posições.

Nesse sentido, a resistência à mudança poderia ser 
interpretada não como um fato da vida organizacional, mas como um padrão de comportamento adotado pelos detentores de poder ou pelos agentes de mudança quando desafiados em sua autoridade, privilégios ou status quo (Agócs, 1997; Smith, 1982).

Pressuposto $n^{0}$ 2: A resistência à mudança é nociva à organização.

A literatura gerencial também tende a enfatizar o lado negativo da resistência: ela é freqüentemente apontada como uma das maiores barreiras a processos bem-sucedidos de transformação organizacional, bem como à introdução de inovações na empresa moderna (para uma revisão desse tipo de afirmação, ver Dent e Goldberg, 1999). Por conseguinte, a resistência passou a ser considerada um fenômeno a ser obstruído ou superado assim que emergir. Entretanto esse pressuposto claramente desconsidera que a resistência à mudança pode, de fato, constituir um fenômeno saudável e positivo. Conceitualmente, a resistência será um fenômeno salutar quando a mudança, de um ponto de vista relativamente objetivo, trouxer prejuízos ao ambiente, ainda que esse não seja o objetivo do agente da mudança (Zaltman e Duncan, 1977). Assim, a resistência à mudança será salutar quando pressionar os agentes da mudança a serem mais cuidadosos ou a modificarem a natureza da mudança a fim de tornála mais compatível com o ambiente ou mesmo quando os indivíduos resistirem às situações opressivas (Agócs, 1997). Tudo isso nos leva ao seguinte contrapressuposto:

Contrapressuposto $\mathrm{n}^{0} 2 \mathrm{a}$ : A resistência é um fenômeno saudável e positivo.

Também não podemos ser ingênuos a ponto de afirmar que o agente da mudança sempre tem razão. Ainda que a resistência à mudança tenha sido considerada o principal fator responsável pelos fracassos em diversos processos de implantação de reengenharia, TQM, automação, downsizing e até mesmo na introdução de novos produtos, parece-nos que essa afirmação (do caráter maligno da resistência) pode visar muito mais proteger a decisão daqueles que se dispuseram a aplicar o remédio certo para o doente errado do que fazer uma real avaliação das razões do fracasso.

Contrapressuposto $n^{0} 2 \mathrm{~b}$ : A resistência é utilizada como uma desculpa para justificar processos de mudança mal desenhados ou malsucedidos.
Pressuposto $n^{0}$ 3: Os seres humanos são naturalmente resistentes a mudanças.

O terceiro pressuposto presente em modelos predominantes de resistência à mudança é aquele que sugere que a resistência é de alguma forma inata à natureza humana. A "lógica" desse pressuposto é a seguinte: a mudança é uma ameaça a um equilíbrio preexistente e, portanto, provocaria incerteza. Assim, os indivíduos "naturalmente" resistiriam à ameaça por meio da adoção de comportamentos resistentes, da mesma forma que o corpo reage a intrusos produzindo defesas naturais. Não obstante, há evidências em contrário. Watson (1969), por exemplo, argumentou que a concepção de que os organismos são natural-

\section{Temos notado que, antes de iniciar esforços de mudança,} poucos agentes de mudança ou consultores avaliam

\section{meticulosamente quem poderia resistir à iniciativa} de transformação específica e por quais motivos.

mente complacentes a menos que tenham sido perturbados por estímulos intrusivos teve de ser revista em função de evidências contraditórias, que mostram que os seres humanos anseiam por estímulo. Para corroborar sua hipótese, o autor cita W. I. Thomas, segundo o qual o "desejo por novas experiências" é um dos quatro mais básicos desejos do comportamento do ser humano. Watson também menciona dois estudos clássicos que mostraram que esse desejo por novas experiências é uma parte fundamental da maioria dos seres vivos, inclusive humanos. Derivamos, assim, o seguinte contrapressuposto:

Contrapressuposto $\mathrm{n}^{0}$ 3a: Seres humanos anseiam por mudança, e tal necessidade comumente sobrepõe-se ao medo do desconhecido.

Pressuposto $n^{0}$ 4: Os empregados são os atores organizacionais que têm maior probabilidade de resistirem à mudança.

$\mathrm{O}$ conceito de resistência à mudança na literatura gerencial também tende a assumir que o papel do gerente ou do agente de mudança é introduzir ou implementar a mudança, enquanto o papel dos empregados é resistir a tal mudança. Dent e Goldberg (1999) lembram-nos de que esse pressuposto é bastante distinto do conceito original de resistência à mudança introduzido por Kurt Lewin nos anos 40. Como já mencionamos, para Kurt Lewin, a resistência à mu- 
dança é um fenômeno sistêmico e, dessa forma, poderia ocorrer tanto com empregados quanto com gerentes. Isso nos leva ao seguinte:

Contrapressuposto $\mathrm{n}^{0}$ 4a (derivado da proposição original de Kurt Lewin): A resistência à mudança é um comportamento que pode ser exibido tanto por gerentes quanto por empregados.

A despeito do conceito original, a difusão da versão gerencialista da teoria de resistência à mudança parece ter creditado a resistência exclusivamente a empregados, em geral, considerados os culpados pelo fracasso na implementação das mudanças. Mais uma vez, o estudo de Coch e French Jr. (1948) - que afirmava que eram os indivíduos menos qualificados e de menor escalão que tenderiam a resistir a mudan- fenômeno individual como grupal - a resistência vai variar de um indivíduo para o outro em função de fatores pessoais e situacionais.

O princípio aqui é que a realidade para um indivíduo pode ser entendida não somente como um fenômeno social e sociopsicológico (Tajfel, 1982; Goffman, 1968) mas também (e em grande extensão) como uma experiência pessoal, isto é, para um ser humano, a realidade é, em grande medida, aquilo que ele(a) percebe como real.

Neste artigo, defendemos que não é possível derivar um modelo completo sobre a resistência à mudança apenas com base nesses pressupostos questionáveis. Se a resistência é ainda vista como uma grande barreira à mudança, isso ocorre justamente porque o modelo predominante é inadequado para captar a sua complexidade e, conseqüentemente, incapaz de ajudar o desenvolvimento de estratégias coerentes para se prevenir ou se lidar com a resistência.

Com a crítica a esses pressupostos clássicos, várias possibilidades para pesquisa abrem-se àqueles interessados em colaborar na construção de um modelo abrangente de resistência à mudança.

ças introduzidas pelos seus superiores - pode ter originado um mito gerencial que foi tomado como verdade inquestionável ao longo dos anos. Conseqüentemente, a questão da mudança passou a ser tratada como uma batalha a ser travada entre empregados e gerentes ou seus consultores. Outros autores têm recentemente se juntado à crítica a esse pressuposto de que "a culpa é dos funcionários". Spreitzer e Quinn (1996), por exemplo, mostraram que gerentes de nível médio de uma organização que passava por processo de mudança culpavam seus superiores hierárquicos por resistir ao esforço de mudança.

\section{Pressuposto $n^{0}$ 5: A resistência à mudança é um fe-} nômeno massificado.

Por fim, o último grande pressuposto nos modelos predominantes de resistência à mudança é o de que os indivíduos resistem homogeneamente. De fato, na maioria das vezes, relatos gerenciais sobre o assunto desconsideram diferenças individuais: as pessoas em organizações são representadas como um corpo homogêneo que demonstra ou que supera a resistência como um agregado. No entanto, para Watson (1969) e outros autores, a resistência não é uniforme e varia de indivíduo para indivíduo de acordo com a fase do processo de mudança. Isso nos levaria ao último contrapressuposto:

Contrapressuposto $\mathrm{n}^{0}$ 5a: A resistência é tanto um
Na seção seguinte, procuraremos contribuir para tal esforço, propondo um Modelo de Resistência Individual à Mudança, usando, por um lado, a Psicologia da Percepção e, por outro, os contrapressupostos antes apresentados.

\section{EM BUSCA DE UM MODELO DE RESISTÊNCIA INDIVIDUAL À MUDANÇA}

Nesta seção, apresentamos a proposta de um novo modelo de resistência às mudanças orientado para o indivíduo, em contraposição ao modelo massificante hoje em vigor. Inicialmente, discutiremos o processo de percepção, base do modelo escolhido a ser apresentado neste artigo e, em seguida, apresentaremos os vários elementos e estágios do modelo proposto.

\section{A dinâmica da percepção: um caminho para se entender a resistência individual à mudança?}

Mencionamos, na seção anterior, que os modelos prevalecentes de resistência à mudança tendem a considerar que os indivíduos resistem de forma homogênea. Essa hipótese desconsidera o fato de que, na maior parte das vezes, os indivíduos percebem os objetos e os acontecimentos de forma pessoal e distinta e, assim, seria de se esperar que as suas reações individuais seguissem o mesmo padrão. Para aqueles que acreditam em resistência uniforme à mudança, os indiví- 
duos teriam a tendência a adotar comportamentos resistentes similares como resposta às mudanças.

Entretanto essa noção de resistência uniforme não é compatível com o conceito amplamente aceito de que a realidade também deve ser entendida como um fenômeno pessoal, baseado nas necessidades, desejos, valores e experiências individuais. Assim, a realidade para cada indivíduo corresponderia à sua percepção individual daquilo que existe ou acontece ao seu redor, e, conseqüentemente, suas ações e reações estariam baseadas na realidade percebida, e não, necessariamente, na realidade objetiva dos fatos e acontecimentos.

De acordo com o nosso ponto de vista, os modelos predominantes de resistência deveriam ser complementados ou totalmente substituídos por novos modelos e teorias. Sugerimos que um desses modelos poderia concentrar-se nas percepções individuais da mudança. Tal modelo também deveria representar, adequadamente, os fatores que podem despertar ou inibir a adoção individual de comportamentos resistentes. Estamos convencidos de que esse modelo, além de estar de acordo, seria uma extensão natural dos conceitos originalmente propostos por Lewin, segundo o qual o indivíduo é um dos "pontos de aplicação" das forças sociais e, portanto, um dos atores sociais que poderia exibir padrões de comportamento resistente. E é nesse ponto que a percepção individual entra em cena.

Percepção foi definida como o processo pelo qual um indivíduo seleciona, organiza e interpreta os estímulos com o objetivo de formar representações significativas e coerentes da realidade (Schiffman e Kanuk, 1991).

Teoricamente, o primeiro estágio do processo de percepção consiste na seleção dos estímulos. A idéia é a de que os indivíduos tendem a buscar as mensagens de forma seletiva, isto é, eles buscam as mensagens que tenham um conteúdo agradável e rejeitam aquelas com conteúdo ameaçador. Pelas mesmas razões, os indivíduos tenderiam a prestar mais atenção às informações que preenchem as suas necessidades e desprezar ou, até mesmo bloquear, a sua percepção de informações consideradas irrelevantes. É o proces-

Quadro 1 - Pressupostos clássicos sobre resistência à mudança e possíveis contrapressupostos

\begin{tabular}{|c|c|}
\hline Pressupostos & Contrapressupostos \\
\hline $\begin{array}{l}\text { A resistência à mudança é um "fato da vida" e deve } \\
\text { acontecer durante qualquer intervenção } \\
\text { organizacional. }\end{array}$ & $\begin{array}{l}\text { A resistência é escassa/somente acontecerá em } \\
\text { circunstâncias excepcionais. } \\
\text { Ao tentar preveni-la, os agentes de mudança acabam } \\
\text { contribuindo para sua ocorrência ou agravamento. } \\
\text { A resistência é um comportamento alardeado pelos } \\
\text { detentores de poder e pelos agentes de mudança } \\
\text { quando são desafiados em seus privilégios ou } \\
\text { ações. }\end{array}$ \\
\hline $\begin{array}{l}\text { A resistência à mudança é maléfica aos esforços de } \\
\text { mudança organizacional. }\end{array}$ & $\begin{array}{l}\text { A resistência é um fenômeno saudável e contributivo. } \\
\text { A resistência é usada como uma desculpa para } \\
\text { processos de mudança fracassados ou } \\
\text { inadequadamente desenhados. }\end{array}$ \\
\hline $\begin{array}{l}\text { Os seres humanos são naturalmente resistentes à } \\
\text { mudança. }\end{array}$ & $\begin{array}{l}\text { Os seres humanos resistem à perda, mas desejam a } \\
\text { mudança: tal necessidade tipicamente se sobrepõe } \\
\text { ao medo do desconhecido. }\end{array}$ \\
\hline $\begin{array}{l}\text { Os empregados são os atores organizacionais com } \\
\text { maior probabilidade de resistir à mudança. }\end{array}$ & $\begin{array}{l}\text { A resistência - quando ocorre - pode acontecer } \\
\text { entre os gestores, agentes de mudança E } \\
\text { empregados (derivado da proposição original } \\
\text { de Lewin). }\end{array}$ \\
\hline $\begin{array}{l}\text { A resistência à mudança é um fenômeno grupal/ } \\
\text { coletivo. }\end{array}$ & $\begin{array}{l}\text { A resistência é tanto individual quanto coletiva - a } \\
\text { resistência vai variar de uma pessoa para outra, em } \\
\text { função de muitos fatores situacionais e de } \\
\text { percepção. }\end{array}$ \\
\hline
\end{tabular}


so de seleção de estímulos que explicaria porque um indivíduo pode não perceber que o status quo pode ser inadequado (Watson, 1971) ou que um indivíduo pode não ser capaz de "ver" problemas que deveriam ser resolvidos ou, mesmo após a identificação do problema, pode não ser capaz de "enxergar" as possíveis soluções (Zaltman e Duncan, 1977). Experimentos clássicos nessa área do conhecimento realizados com o objetivo de provocar mudanças nas atitudes dos indivíduos revelaram que estes podem não ouvir claramente, não se lembrar ou mesmo distorcer informações quando não concordam com o seu conteúdo cognitivo (Levine e Murphy, 1943).
O processo de percepção também depende da quantidade e da qualidade dos estímulos interiores e exteriores. Os estímulos exteriores são proporcionados pelo ambiente e detectados pelos sentidos. Como os indivíduos estão constantemente expostos a uma grande quantidade de estímulos provenientes do ambiente, eles acabam por desenvolver mecanismos de defesa para não ficarem completamente desorientados. Esse mecanismo de defesa é representado pelos estímulos interiores, que emergem na forma de predisposições, tais como expectativas, motivos e lições aprendidas, todas baseadas em experiências anteriores. A combinação desses dois tipos de estímulos, interiores e exteriores, proporciona aos indivíduos representações distintas e individuais da realidade.

Quando aplicada ao estudo da resistência às mudanças organizacionais, essa linha de pensamento é bastante útil para entendermos por que, dados dois indivíduos, na presença das mesmas condições de mudança, cada um deles terá percepções bastante distintas. Embora possam compartilhar da mesma realidade objetiva, duas pessoas nunca terão compartilhado as mesmas experiências, desejos, necessidades e expectativas.

O segundo estágio da dinâmica da percepção corresponde à organização dos estímulos. A crença é a de que os indivíduos organizam, regularmente, os estímulos em categorias que são recuperadas como um todo, uma vez que, se cada indivíduo percebesse cada estímulo como sendo único, ele não poderia se lembrar de mais do que uma mínima fração do que geralmente percebe (Smith e Medin, 1981). Obviamente, diferentes indivíduos costumam organizar os estímulos de diferentes formas e esse fato também é bastante relevante para se compreender as situações de mudança organizacional. Por exemplo, Zaltman e Duncan (1977) descrevem dois casos em que os agentes da mudança e os seus clientes concordavam sobre a natureza do problema, mas não compartilhavam a mesma percepção sobre como o problema deveria ser resolvido.

O terceiro e último estágio, a interpretação perceptual, também tem uma natureza individual, uma vez que depende das expectativas dos indivíduos originadas de suas experiências anteriores, do número de interpretações possíveis que eles podem antever e dos seus interesses no momento da percepção (Schiffman e Kanuk, 1991).

\section{O Modelo de Resistência Individual à Mudança}

A tentativa de explicar a resistência às mudanças ou inovações por meio do processo de percepção não é nova. Bagozzi e Lee (1999), baseados na Psicologia da Ação, propuseram um modelo analítico que pretende explicar a resistência e aceitação dos consumidores às inovações introduzidas por fabricantes de produtos de consumo. Considerando que a resistência às inovações é um caso especial de resistência às mudanças, como os autores afirmam, iremos adaptar e complementar seu modelo para ilustrar o processo de percepção de mudanças e inovações organizacionais.

Nosso modelo amplia e complementa o modelo de Bagozzi e Lee em pelo menos duas dimensões críticas. Em primeiro lugar, utilizando-nos de referências recentes da teoria da percepção, principalmente aquelas originadas no estudo da Teoria da Categorização (por exemplo, Hartman et al., 1990), adicionamos um estágio inicial de processamento de informações. Em segundo lugar, incluímos também o efeito moderador das variáveis individuais e situacionais ao modelo (apesar de Bagozzi e Lee terem reconhecido a importância do efeito das variáveis in- 
dividuais sobre o processo de aceitação e resistência dos consumidores às inovações, eles não as incluíram explicitamente em seu modelo, preferindo concentrar-se nos estágios de processamento das informações).

Em nossa opinião, as variáveis individuais e situacionais são tão ou mais importantes que o processo de percepção em si mesmo, uma vez que, em condições de mudança organizacional, essas variáveis moderam todos os estágios do processo de percepção da mudança, influenciando a maneira como cada indivíduo cria a sua própria representação da realidade.

De forma geral, nosso modelo de resistência individual às mudanças compreende uma série de sete estágios que podem resultar em quatro tipos diferentes de resultados: a) adoção espontânea da mudança; b) decisão para se superar a resistência à mudança; c) adoção de um comportamento resistente; d) indecisão. No restante desta seção, discutiremos brevemente cada um dos estágios do modelo individual de re- sistência (ver Figura 1). Vamos concentrar-nos, particularmente, no papel das variáveis individuais e situacionais, tentando ilustrar a discussão com resultados de estudos que analisaram a relevância desses fatores em processos de mudanças organizacionais (para mais detalhes sobre cada um dos estágios, veja Bagozzi e Lee (1999) e Hartman et al. (1990)).

\section{Estágios}

O primeiro estágio (1. Exposição à Mudança ou Inovação) é caracterizado pelo contato inicial do indivíduo com a intenção da mudança ou com informações sobre ela. Tais intenções ou informações podem ser transmitidas pelos agentes da mudança por intermédio dos canais formais e informais da organização ("radiocorredor"). Estudos anteriores (por exemplo, Greenhalgh e Rosenblatt, 1984) concentraram-se na importância desse estágio na percepção das mudanças e em seus resultados como a insegurança no trabalho e a adoção de comportamentos resistentes. A natureza desses estímulos freqüentemente é ambígua,

Figura 1 - Modelo de Resistência Individual à Mudança

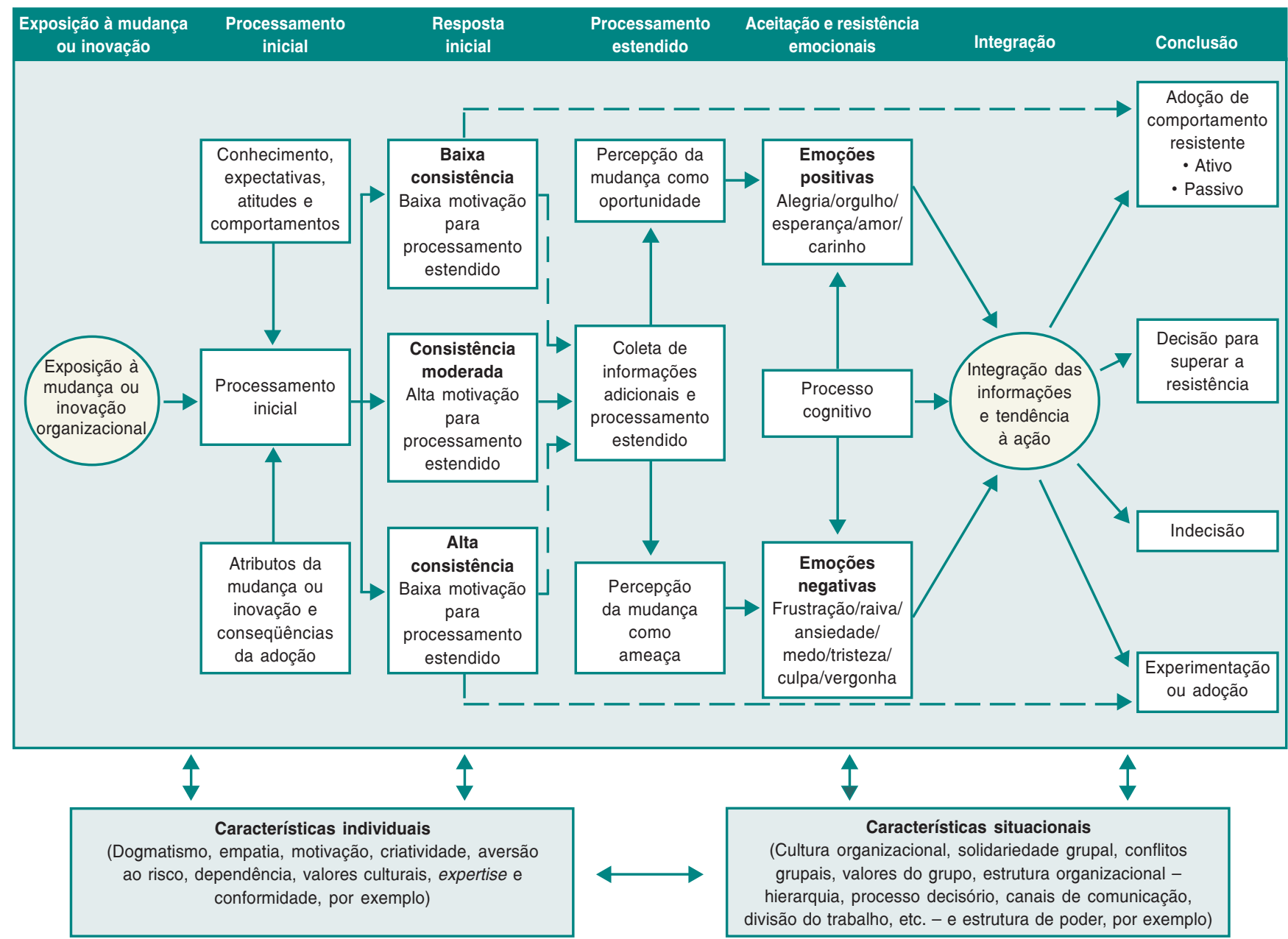


uma vez que eles dependem não apenas das condições objetivas do ambiente mas também da relação existente entre o indivíduo e o seu ambiente. Por esses motivos, é razoável supor que os mesmos estímulos serão percebidos de formas distintas por indivíduos diferentes compartilhando o mesmo ambiente organizacional, dando espaço à formação de diversas interpretações.

Uma vez estimulado interior ou exteriormente, durante o segundo estágio (2. Processamento Inicial), o indivíduo irá comparar os atributos percebidos da mudança com as conseqüências previstas e com as suas expectativas, atitudes e comportamentos adotados no passado. O resultado desse processo de comparação é crítico para se determinar se, no próximo estágio (3. Resposta Inicial), o indivíduo apresentará uma aceitação inicial ou uma rejeição inicial, que, por sua vez, pode ter natureza ativa ou passiva. Três são os resultados possíveis desse processo: percepção de baixa consistência, moderada consistência ou alta consistência.

O indivíduo irá exibir rejeição inicial em situações de baixa consistência, isto é, quando os atributos da mudança proposta e as conseqüências previstas da sua adoção não puderem ser conciliados com o seu conhecimento ou não fizerem sentido quando comparados às suas atitudes e comportamentos adotados no passado. Nessa situação, é provável que ele não se sinta estimulado a continuar a avaliação da proposta de mudança, decidindo-se por rejeitá-la. Essa rejeição inicial pode ter natureza ativa ou passiva.

Várias razões justificam a adoção de um comportamento inicial de rejeição de natureza ativa. Por exemplo, Maurer (1997) indicou a inclinação que as pessoas têm a resistir às idéias que elas acreditem que possam causar-lhes algum mal; Abbasi e Holman (1993) propõem que as pessoas são avessas ao risco e tenderão a rejeitar mesmo as alternativas consideradas aceitáveis ou atrativas; Kotter e Schlesinger (1979) enumeraram quatro razões típicas para as pessoas resistirem à mudança nesse estágio: a) desejo de não perder algo considerado valioso; b) incompreensão sobre as razões da mudança e suas implicações; c) crença de que a mudança não faz sentido para a organização; d) baixa tolerância à mudança.

Uma das causas mais comuns para a ocorrência da rejeição inicial de natureza passiva é o hábito (Watson,1969), ou seja, a tendência que os indivíduos têm a responder aos estímulos da mesma forma como sempre o fizeram. O segundo fator que pode levar à rejeição passiva da mudança é a persistência na manutenção de comportamentos anteriores, isto é, a forma como um indivíduo lidou com um problema pela primeira vez pode estabelecer um padrão de comportamento no futuro (Watson, 1969).

Quando a resistência tem uma natureza ativa,o indivíduo tentará de todas as formas possíveis evitar que a organização mude ou inove, podendo adotar, como conseqüência, diferentes comportamentos: protesto, sabotagem ou enfrentamento. O comportamento do indivíduo que tem uma rejeição inicial passiva, por sua vez, é diferente: ele pode simplesmente decidir por ignorar as mudanças ou agir como se nada tivesse acontecido.

O segundo resultado possível desse estágio é a percepção de alta consistência: esse tipo de resposta ocorre quando o indivíduo rapidamente conclui, após o processamento inicial, que os atributos da mudança e suas conseqüências são aceitáveis ou fazem sentido. Nesse caso, o indivíduo vai-se mostrar disposto a aceitar a mudança ou inovação prontamente e não sentirá a necessidade de aprofundar a avaliação da sua proposta.

Por fim, o terceiro resultado possível desse estágio, a consistência moderada, ocorre quando o indivíduo percebe que os atributos da mudança e suas conseqüências são parcialmente aceitáveis. Esse é o caso mais freqüente, no qual o indivíduo vai-se sentir estimulado a buscar novas informações sobre a mudança proposta, iniciando-se, assim, o estágio de processamento estendido. O modelo prevê explicitamente que, ainda que o indivíduo tenha percebido haver alta ou baixa consistência durante o estágio inicial, ele pode entrar na fase de processamento estendido, influenciado pelas variáveis individuais (Childers et al., 1985) ou situacionais (Belk, 1975). Estudos anteriores mostraram que pessoas podem ser influenciadas a estender sua avaliação do processo de mudança, a despeito da sua propensão inicial em contrário, em função de fatores como envolvimento (Hartman et al., 1990), aversão ao risco (Zaltman e Duncan, 1977), dogmatismo (Rogers e Shoemaker, 1971) e insegurança (Watson, 1969).

Durante o quarto estágio do processo (4. Processamento Estendido), o indivíduo irá avaliar, mais cuidadosamente, os atributos da mudança proposta, tentando reconciliar as inconsistências encontradas entre esses atributos e o seu conhecimento com o objetivo de diminuir a sua dissonância. Naturalmente, esse estágio tem um ciclo mais longo do que o estágio de processamento inicial, não apenas porque a busca de informações adicionais demora mais, mas também porque o processo cognitivo do indivíduo tende a ser mais lento. O resultado dessa avaliação é a percepção da mudança como oportunidade, ameaça ou, em al- 
guns casos, oportunidade e ameaça ao mesmo tempo.

No decorrer do próximo estágio (5. Aceitação e Resistência Emocionais), formam-se as emoções, estados mentais que surgem como resultado de comparações conscientes e inconscientes, geralmente de natureza automática, entre a situação real e a situação almejada. Caso a mudança proposta tenha sido percebida como oportunidade, as emoções resultantes são positivas e podem incluir amor, carinho, orgulho, paz, etc. A resistência emocional, por sua vez, é o resultado da formação de emoções negativas, tais como medo, angústia, tristeza, raiva, culpa, vergonha, etc. Sem dúvida alguma, o processo cognitivo individual influencia a formação dessas emoções e a adoção correspondente de comportamentos de resistência ou aceitação (Bagozzi e Lee, 1999).

Durante o sexto estágio (6. Integração) do modelo, o indivíduo tentará integrar todas as emoções e respostas cognitivas geradas no estágio anterior. Como resultado desse processo, durante o sétimo estágio (7. Conclusão), o modelo prevê que o indivíduo pode adotar quatro diferentes possibilidades de comportamentos: a) resistência; b) decisão de superar a resistência; c) indecisão; d) adoção (ou teste) da mudança.

A decisão de adotar a mudança ou ao menos testála parece clara. A decisão de superar a resistência, por sua vez, surgirá quando, apesar da propensão do indivíduo a resistir à mudança, ele não se sentir confortável com tal decisão, seja porque ele ache que o ímpeto para resistir se origina em medos irracionais, seja porque o grupo o está pressionando a manter a conformidade. O comportamento resistente aparecerá quando o indivíduo se sentir confortável com tal situação, a despeito de todos os estímulos interiores e exteriores para que ele aceite a mudança ou mesmo quando o grupo o pressiona a resistir. A indecisão surgirá quando o indivíduo não for capaz de integrar todas as informações e as respostas cognitivas e emocionais a que ele foi exposto, quando a decisão for muito complexa ou, ainda, quando a capacidade cognitiva individual for insuficiente para lidar com o conflito.

Naturalmente, o modelo tem uma natureza cíclica: em qualquer ponto durante o processo de percepção, o indivíduo pode ser confrontado com novos estímulos interiores e exteriores (por exemplo, novas informações, novas emoções, novas pressões do grupo, etc.). Estímulos diferentes, por sua vez, o levariam a reavaliar os atributos e as conseqüências potenciais da mudança, a reavaliar a percepção da mudança como oportunidade ou como ameaça e, portanto, a reavaliar o seu comportamento em relação ao esforço da mudança.

\section{O papel dos moderadores individuais e situacionais}

Quando falamos em variáveis ou moderadores individuais, referimo-nos àquelas características dos indivíduos que influenciam seu processo cognitivo. A literatura sobre o assunto geralmente inclui entre essas variáveis não apenas atributos da personalidade como dogmatismo, empatia, falta de habilidade em lidar com abstrações ou com a ambigüidade, fatalismo, motivação, criatividade, aversão ao risco, depen-

\section{Tão importante quanto a análise das causas da} resistência, particularmente para a mudança organizacional, é a identificação dos grupos e indivíduos que terão maior inclinação a resistir à mudança e das razões desse comportamento.

dência, auto-estima, insegurança e resiliência (Rogers e Shoemaker, 1971; Zaltman e Duncan, 1977; Watson, 1969; Conner, 1993; Rosenblatt e Ruvio, 1996), mas também valores culturais, crenças, etnocentrismo cultural, conformidade e imperativos para o comprometimento (Zaltman e Duncan, 1977; Watson, 1969).

A literatura sobre mudança organizacional e inovação explorou, profundamente, algumas dessas variáveis e seu relacionamento com o processo de avaliação de mudanças e adoção de comportamentos enquanto outras ficaram completamente inexploradas. Por exemplo, o dogmatismo, isto é, a propensão a rejeitar novas idéias, é, freqüentemente, citado na literatura como uma das barreiras potenciais às iniciativas às mudanças. Sabemos que os indivíduos compartilham graus diferentes de dogmatismo, sendo razoável supor que indivíduos exibindo maior grau de dogmatismo têm uma tendência maior a adotar comportamentos resistentes. Assim, ainda que os atributos de uma determinada iniciativa de mudança façam sentido para um indivíduo dogmático, devemos esperar que a sua tendência a adotar um comportamento resistente seja maior do que a daqueles indivíduos que compartilham a mesma opinião sobre os atributos da mudança, mas que não apresentam um grau tão ele- 
vado de dogmatismo. De acordo com Rogers (1962), o grau de dogmatismo é uma das explicações para o fato de que uma inovação pode ser atrativa para os inovadores e, ao mesmo tempo, ser alvo da resistência dos indivíduos mais conservadores.

Outro fator também comumente citado na literatura como barreira às mudanças é o medo do desconhecido (Dent e Goldberg, 1999). Entretanto, se assumirmos que todos os indivíduos irão resistir da mesma forma à iniciativa de automação de uma filial de uma instituição financeira pelo medo do desconhecido que tal iniciativa poderia representar, estaríamos desconsiderando diversas diferenças individuais. Por exemplo, alguns indivíduos em particular dessa filial poderiam ser experts em automação e, provavelmente, sentiriam-se aliviados com a mudança, uma vez que suas tarefas seriam facilitadas; o gerente dessa filial poderia não se sentir de forma alguma afetado por essa mudança considerando-se que ele está prestes a se aposentar; outros poderiam ver na mudança uma oportunidade para autodesenvolvimento e, eventualmente, uma oportunidade para conseguir melhores empregos no futuro. As possibilidades são absolutamente infinitas.

O outro grupo de fatores que moderam o processo de percepção e avaliação das mudanças é o de variáveis situacionais. Esses fatores referem-se aos estímulos proporcionados pelo ambiente no qual o indivíduo está inserido; mais especificamente, eles geralmente são provenientes do grupo a que o indivíduo pertence ou da organização propriamente dita, por meio dos seus canais formais e informais de comunicação.

Em relação a esses moderadores situacionais, estudos anteriores mostraram que fatores tais como a cultura organizacional, solidariedade grupal, crenças compartilhadas, existência de conflitos internos, necessidade de conformidade, comprometimento da alta gerência com o processo de mudança, inércia organizacional, tipo de poder existente na organização e na estrutura organizacional (hierarquia, processo decisório, canais de comunicação, divisão do trabalho, etc.) podem exercer influência sobre a percepção individual e influenciar a adoção de comportamentos resistentes (Watson, 1969; Zaltman e Duncan, 1977).

A cultura de uma organização, por exemplo, pode ter entronizado valores nos membros da organização que influenciarão sua forma de perceber processos de mudança. Para ilustrar esse ponto, é de se supor que em uma organização cuja cultura valorize a inovação, os seus membros sintam-se menos inclinados a resistir a processos de mudança que introduzam inovações do que indivíduos pertencentes a organizações com uma cultura menos progressista. No entanto, mesmo em organizações com culturas que valorizam a inovação, é possível encontrar indivíduos que resistirão às mudanças como uma forma de desafiar a cultura em si mesma ou como forma de se destacar politicamente.

A dinâmica intergrupal também é um dos moderadores situacionais bem explorados na literatura (Tajfel, 1982; Brown e Williams, 1984; Kramer, 1993). Por exemplo, em uma organização onde exista conflito de interesses entre determinados grupos, é de se esperar que os membros de um desses grupos estejam mais inclinados a resistir às mudanças propostas por um grupo rival do que se a proposta tivesse partido de grupos aliados.

\section{DISCUSSÃO}

O Modelo de Resistência Individual à Mudança apresentado neste estudo pretende revisitar e estender as propostas feitas pelos primeiros teóricos que se debruçaram sobre o fenômeno da resistência às mudanças em ambientes organizacionais. Acreditamos que o nosso modelo oferece uma contribuição significativa para o desenvolvimento da pesquisa e prática no campo da resistência às mudanças organizacionais. Nesta seção, apontaremos algumas dessas contribuições e as principais limitações do modelo.

\section{Contribuições teóricas e práticas}

Este estudo oferece pelo menos duas contribuições teóricas significativas. Em primeiro lugar, relembranos que talvez se saiba muito menos sobre resistência às mudanças organizacionais - o que é, quando e por que ela ocorre, quais as suas conseqüências e como lidar com ela - do que teóricos e práticos pensam que sabem. O artigo recorda-nos desse fato por intermédio da revisão e do questionamento dos cinco pressupostos geralmente aceitos a respeito da resistência à mudança e que foram assumidos como verdade por gerentes e teóricos desde o surgimento dos primeiros estudos empíricos a respeito no final dos anos 40.

Como mencionamos anteriormente, nos primeiros estudos sobre o tema, os autores freqüentemente consideravam a resistência como um fenômeno grupal ou individual (por exemplo, Lewin, 1951; Watson, 1969); como uma circunstância não necessariamente a ser superada, mas como uma pista de que existiam problemas reais, estes, sim, a serem resolvidos (Lawrence, 1954); ou como um evento não necessariamente nocivo e, eventualmente, até mesmo saudável (Lawrence, 1954; Watson, 1969). 
Por estranhas razões, entretanto, depois que alguns estudos gerencialistas - muito difundidos, mas não necessariamente rigorosamente testados - surgiram no início da década de 50 , o fenômeno da resistência à mudança passou a ser considerado resolvido e compreendido. Discussões sucessivas e artigos recomendando "receitas" aos praticantes das mudanças organizacionais surgidos em anos recentes continuaram reforçando os mesmos pontos e reproduzindo as mesmas hipóteses a um tal ponto que esse modelo clássico atingiu um status de "verdade absoluta". A revisão dessas hipóteses e as críticas elaboradas neste estudo são um convite para a exploração de um novo caminho de pesquisa sobre as razões, as situações e as formas em que a resistência se manifesta.

Em segundo lugar, este artigo utiliza-se de alguns contrapressupostos às premissas clássicas e da Psicologia da Percepção para propor um novo Modelo de Resistência Individual à Mudança, tomando como unidade de análise o indivíduo. Além de seu valor inerente como um modelo descritivo e potencialmente preditivo, acreditamos que o uso de teorias recentes sobre a percepção e o foco na dimensão individual do fenômeno da resistência à mudança é uma contribuição estimulante a esse campo de estudo.

Nosso estudo também é um convite aos agentes de mudança e aos praticantes a repensar a abordagem que considera a resistência como um problema em si mesmo. Ao compartilharem a hipótese geralmente aceita de que a resistência deve ser identificada e superada, os agentes da mudança desconsideram a possibilidade (presente na teoria desde Lawrence, 1954) de que a resistência pode ser um sinal de que existe uma situação problemática anterior à sua ocorrência e que ela não é o problema. Portanto, esse estudo relembra aos praticantes de que eles deveriam se concentrar mais na identificação das causas da resistência do que no seu combate.

Por fim, o modelo proposto também pode ser uma ferramenta útil para uma análise sobre as possíveis causas da resistência à mudança que seja centrada no indivíduo; afinal, o estudo nos relembra de que a investigação de causas gerais e massificantes é insuficiente, já que tentamos demonstrar (e acreditamos ter tido sucesso nessa tarefa) que indivíduos diferentes reagirão de formas distintas aos mesmos estímulos. Portanto, tão importante quanto a análise das causas da resistência, particularmente para a mudança orga- nizacional, é a identificação dos grupos e indivíduos que terão maior inclinação a resistir à mudança e das razões desse comportamento.

\section{Limitações}

Naturalmente, como qualquer proposição inicial, o modelo aqui apresentado tem diversas limitações que deveriam ser complementadas ou corrigidas em futuros desenvolvimentos.

\section{Ainda que tanta prática já devesse ter levado}

\section{à perfeição, a verdade é que a maioria}

\section{das organizações ainda luta para conduzir}

\section{transformações de forma efetiva.}

Por exemplo, ele não tem por objetivo explicar e prever todas as dimensões envolvidas no complexo fenômeno que é a resistência às mudanças, concentrando-se apenas na dimensão da percepção individual. Apesar disso, é nossa crença que, entre outras dimensões do fenômeno da resistência (institucional, cultural, organizacional, etc.), a percepção individual apresentada aqui seja um caminho crítico em direção a uma compreensão maior e mais rica de por que pessoas ou organizações podem resistir a mudanças.

Em relação às limitações do modelo, é importante ressaltar que ele foi inspirado em outros modelos tais como o de Bagozzi e Lee (1999), desenvolvido especificamente para se analisar a adoção de comportamentos resistentes de consumidores à vista de inovações propostas por fabricantes de produtos de consumo. Embora nosso modelo tenha sido extensamente revisado e complementado, incluindo-se aí a adição das variáveis individuais e situacionais e muitos outros elementos da literatura da mudança organizacional, a inspiração ainda está lá. O bom senso nos diz que as inovações de marketing compreendem uma categoria de estímulos muito mais concreta do que aqueles apresentados às organizações e seus empregados durante mudanças organizacionais. Apesar da existência de indicativos de que o processo de percepção seja semelhante e de que as adaptações do nosso modelo foram meticulosas, não existem evidências empíricas que suportem completamente o uso dessa analogia.

Nesse sentido, a Teoria da Categorização, utilizada extensivamente para explicar a percepção de novos conceitos em diversas disciplinas, tais como Edu- 
cação (Rosch, 1973) e Psicologia (Smith e Nelson, 1984), poderia servir como um quadro de análise conceitual bastante apropriado para complementar esse modelo. Embora a Teoria da Categorização tenha sido utilizada inicialmente na literatura cognitiva na identificação de conceitos e na percepção de objetos, de acordo com Cohen e Basu (1987), sua utilização na pesquisa social tem-se tornado cada vez mais freqüente. Por exemplo, ela foi utilizada para explicar como os indivíduos formam suas impressões sobre outros indivíduos (Cantor e Mischel, 1979) e para descrever como selecionam comportamentos em determinadas situações (Wyer e Srull, 1981).

Outra limitação do modelo relaciona-se à natureza ainda inexplorada dos mecanismos cognitivos utilizados por indivíduos quando confrontados com mudanças. No modelo de Bagozzi e Lee (1999), emoções emergem como resultado de uma comparação automática entre os estados atual e desejado pelo indivíduo. Outros modelos cognitivos (Cohen e Basu, 1987) podem adaptar-se melhor ao modelo individual de resistência à mudança.

Finalmente, o modelo ressalta a importância dos moderadores individuais e situacionais, mas não desenvolve profundamente seu relacionamento com o processo de percepção de mudanças. Esse fato se deve ao limitado número de estudos teóricos correlacionando essas variáveis. Embora tenhamos revisto uma grande variedade de estudos empíricos com esse objetivo, novos estudos deveriam ser realizados para se verificar, consistentemente, que variáveis têm maior probabilidade de exercer influência sobre o processo de percepção individual durante mudanças organizacionais.

\section{CONCLUSÃO}

Este artigo revê e examina os modelos e teorias predominantes sobre a resistência às mudanças organizacionais e conclui que a) as "receitas" por eles recomendadas não têm sido eficientes nem na prevenção nem na superação da resistência à mudança organizacional e b) a origem desse problema reside nos pressupostos inadequadamente testados que tais modelos herdaram das propostas clássicas sugeridas no final da década de 40 e, desde então, assumidas como verdadeiras pelo senso comum gerencial. Esses pressupostos, cada vez mais contestados nos dias de hoje, tanto por teóricos quanto por praticantes, retratam a resistência como a) um fato natural e inevitável; b) algo nocivo às organizações e às iniciativas de mudança; c) algo que ocorre apenas entre empregados e d) um fenômeno massificando (isto é, organizações são retratadas como corpos indistintos inclinados a resistir à mudança).

Este estudo critica, estruturadamente, esses pressupostos e apresenta alguns contrapressupostos que acreditamos que também deveriam passar a ser utilizados na geração de novos modelos e teorias operacionais sobre quando, como e por que ocorre a resistência à mudança.

Baseados nesses contrapressupostos e em conceitos contemporâneos da Psicologia da Percepção, apresentamos um novo Modelo de Resistência Individual à Mudança, utilizando o indivíduo como unidade de análise. Esse modelo representa o processo perceptual individual em situações de mudança organizacional, compreendendo uma série de sete estágios desde a exposição aos estímulos apresentados pelo ambiente até a adoção de um comportamento, cujos resultados possíveis são: a) adoção de um comportamento resistente; b) decisão para superar a resistência; c) indecisão; d) adoção espontânea da mudança. $\mathrm{O}$ modelo também inclui, explicitamente, a presença de dois conjuntos de variáveis (individuais e situacionais) que podem exercer influência sobre o processo de percepção.

Acreditamos que o modelo apresentado aqui pode ser uma ferramenta útil para agentes de mudança conscientes das limitações dos modelos clássicos e que estejam buscando formas mais eficientes para lidar com o fenômeno da resistência à mudança nas organizações. Estamos convencidos de que tal modelo pode contribuir, significativamente, na avaliação da propensão individual a adotar comportamentos resistentes, bem como na prevenção e na superação da resistência em processos de intervenção. Nosso objetivo é o de que, ao utilizar o modelo e identificar as razões pelas quais os indivíduos resistem, os agentes de mudança possam desenvolver estratégias melhores e mais adequadas a cada circunstância específica. $\bigcirc$

REFERÊNCIAS BIBLIOGRÁFICAS

ABBASI, S. M., HOLLMAN, K. W. Inability to adapt: the hidden flaw of managerial ineptness. Records Management Quartely, v. 27, n. 1, p. 22-25, 1993.
AGóCS, C. Institutionalized resistance to organizational change: denial, inaction and repression. Journal of Business Ethics, Dordrecht, v. 16, n. 9, p. 917-931, 1997.
BAGOZZI, R. P., LEE, K. Consumer resistance to, and acceptance of, innovations. In: ARNOULD, E. J., SCOTT, L. M. (Eds.). Advances in Consumer Research, v. 26, p. 218225, 1999. 
BELK, Russel W. Situational variables and consumer behavior. Journal of Consumer Research, Chicago, v. 2 , n. 3, p. 157-164, Dec. 1975.

BOYLE, R. D. Avoiding common pitfalls of reengineering. Management Accounting, Montvale, v. 77, n. 4, p. 24-30, 1995.

BRAVER, N. Overcoming resistance to TQM. ResearchTechnology Management, Washington, v. 38, n. 5, p. 4044, 1995.

BROWN, R., WILLIAMS, J. Group identification: the same thing to all people? Human Relations, New York, v. 37, n. 7 , p. $547-564,1984$

BURKE, W. W. Organization development: a normative view. Reading, MA : Addison-Wesley, 1987.

CANTOR, N., MISCHEL, W. Prototypes in person perceptions. In: BERKOWITZ, L. (Ed.). Advances in Experimental Social Psychology. New York: Academic Press,1979. V. 12, p. 3-52.

CHILDERS, Terry L., HOUSTON, M., HECKLER, S. Measurement of individual differences in visual versus verbal information processing. Journal of Consumer Research, Chicago, v. 12, n. 2, p. 125-134, Sept. 1985.

COCH, L., FRENCH JR., J. R. P. Overcoming resistance to change. Human Relations, New York, v. 1, n. 4, p. 512-532, 1948.

COGHLAN, D. A person-centred approach to dealing with resistance to change. Leadership and Organization Development Journal, v. 14, n. 4, p. 10-14, 1993.

COHEN, J. B., BASU, K. Alternative models of categorization: toward a contingent processing framework. Journal of Consumer Research, Chicago, v. 13, n. 4, p. 455-472, Mar. 1987.

CONNER, D. R. Managing change: a business imperative. Business Quarterly, v. 58, n. 1, p. 88-92, Autumm 1993.

DENT, E. B., GOLDBERG, S. G. Challenging 'resistance to change'. The Journal of Applied Behavioral Science, Thousand Oaks, v. 35, n.1, p. 25-41, 1999.

GOFFMAN, E. Stigma. Hardmon : Penguin, 1968

GREENHALGH, L., ROSENBLATT, Z. Job insecurity: toward conceptual clarity. Academy of Management Review, Briarcliff Manor, v. 9, n. 3, p. 438-448, 1984

HARTMAN, C. L., PRICE, L. L., DUNCAN, C. P. Consumer evaluation of franchise extension products: a categorization processing perspective. In: GOLDBERG, M. E. etal. (Eds.). Advances in Consumer Research, v. 17, p. 120-127, 1990.

HAZAN, E. Deregulation: the show goes on. Transmission \& Distribution World, v. 50, n. 3, p. 49-56, 1998.

HOLPP, L. 10 reasons why Total Quality is less than total. Training, v. 26, n. 10, p. $93,1989$.
ISKATT, G. J., LIEBOWITZ , J. What to do when employees resist change. Supervision, v. 57, n. 8, p. 3-5, 1996.

JOSHI, K. A model of users' perspective on change: the case of information systems technology implementation. MIS Quarterly, Minneapolis, v.15, n. 2, p. 229-242, 1991.

KOTTER, J. P. Leading change: why transformation efforts fail. Harvard Business Review, Boston, v. 73, n. 2, p. 59-67, Mar.1995.

KOTTER, J. P. SCHLESINGER, L. A. Choosing strategies for change. Harvard Business Review, Boston, v. 57, n. 2, p. 106-113, Mar./Apr. 1979.

KRAMER, R. M. Organizational identification and cooperation. In: MURNIGHAN, K. (Ed.). Social psychology in organizations: advances in theory and practice. Englewood Cliffs, NJ : Prentice-Hall, 1993.

KURTZ, P., DUNCAN, A. Shared service centres: overcoming resistance to implementation of a shared service centre. Management Accounting, Montvale, v. 76, n. 7, p. 47-48, 1998.

LAPLANTE, A. Resistance to change can obstruct computing strategy. InfoWorld, v. 13, n. 23, p. S59-S63, 1991.

LAWRENCE, P. R. How to deal with resistance to change Harvard Business Review, Boston, v. 32, n. 3, p. 49-57, 1954

LEVINE, M. M., MURPHY, G. The learning and forgetting of controversial material. Journal Abn. Sociology and Psychology, v. 38, p. 507-517, 1943.

LEWIN, K. Frontiers in group dynamics. Human Relations, New York, v. 1, n. 1, p. 5-41, 1947

LEWIN, K. Field theory in social science. New York : Harper and Row, 1951

LIPTON, M. When clients resist change. Journal of Management Consulting, v. 9, n. 2, p. 16-21, 1996.

LIU, C. K. Pitfalls of Total Quality Management in Hong Kong Total Quality Management, v. 9, n. 7, p. 585-598, 1998.

MAURER, R. Transforming resistance: using resistance to make change happen. Human Resources Professional, v. 10, n. 6, p. 3-6, 1997.

MILLER, R. L., CANGEMI, J. P. Why Total Quality Management fails: perspective of top management. Journal of Management Development, v. 12, n. 7, p. 40-50, 1993.

POE, C. D., VIATOR, R. E. What to do when employees resis automation. Journal of Accounting and EDP, v. 5, n. 4, p. 9 14, 1990.
ROGERS, E. M. Diffusion of innovations. New York : The Free Press, 1962

ROGERS, E. M., SHOEMAKER, F. F. Communication of innovations: a cross-cultural approach. New York: The Free Press, 1971.

ROSCH, E. On the internal structure of perceptual and semantic categories. In: MOORE, T. E. (Ed.). Cognitive development and the acquisition of language. New York: Academic Press, 1973. p. 111-144.

ROSENBLATT, Z, RUVIO, A. A test of multidimensional model of job insecurity: the case of Israeli teachers. Journal of Organizational Behavior, West Sussex, v. 17, p. 587605, Dec. 1996. Special issue.

SCHIFFMAN, L., KANUK, L. Consumer behavior. 4. ed. New Jersey : Prentice-Hall, 1991.

SMITH, K. K. Groups in conflict: prisons in disguise. Dubuque, lowa : Kendall/Hunt Pub. Co., 1982.

SMITH, E. W., MEDIN, D. L. Categories and concepts. Cambridge, MA : Harvard University Press, 1981.

SMITH, J. D., NELSON, D. G. K. Overall similarity in adult's classification: the child in all of us. Journal of Experimental Psychology, v. 113, n. 1, p.137-139, 1984.

SPREITZER, G. M., QUINN, R. E. Empowering middle managers to be transformational leaders. Journal of Applied Behavioral Science, Thousand Oaks, v. 32, n. 3, p. 237261, 1996.

TAJFEL, H. Social psychology of intergroup relations. In: ROSENWEIG, M. R., PORTER, L. W. (Eds.). Annual Review of Psychology, Palo Alto, CA, v. 33, p. 1-39, 1982. Annual Reviews.

WATSON, G. Resistance to change. In: BENNIS, W. G. et al. (Eds.). The planning of change. New York: Holt, Rinehart and Winston, 1969.

WATSON, G. Resistance to change. American Behavioral Scientist, Thousand Oaks, v.14, p. 745, May 1971.

WYER, R. S., SRULL, T. K. Category accessibility: some theoretical and empirical issues concerning the processing of social stimulus information. In: HIGGINS, E. et al. (Eds.) Social cognition: the Ontario Symposium, v. 1, p. 161. Hillsdale, NJ: Erlbaum, 1981.

ZALTMAN, G., DUNCAN, R. Strategies for planned change. New York: Wiley \& Sons, 1977

ZANDER, A. F. Resistance to change: its analysis and prevention. Advanced Management, New York, v. 4, n. 5 , p. $9-11,1950$

NOTA

Versões preliminares deste artigo foram apresentadas no Enanpad 2000 (área de Recursos Humanos) e na reunião anual de 2000 da Academy of Management (MC Division/ ODC Division). 